\title{
Analysis of Rural Rubbish Problem Based on PPP Mode and Its Countermeasures
}

\author{
- A Case Study of Shandong Province \\ Jialin Song ${ }^{1 . a}$ Jianing Liu $^{1, b}$ \\ ${ }^{1}$ Shandong University, Weihai, Shandong, China, 264209 \\ ${ }^{\mathrm{a} e m a i l,}{ }^{\mathrm{b}}$ email,
}

Keywords: Rural Rubbish Problem PPP Mode, Problem, Countermeasures, Shandong Province

\begin{abstract}
Rural waste disposal is related to beautiful rural construction, rural green and healthy development and comprehensive well-off quality and it has got the community's attention in recent years. In this paper, the present situation and existing problems of rural waste management in Shandong Province are deeply studied, and the application of PPP (government and social capital cooperation) model in rural waste disposal is discussed from the perspective of rural waste management model. Combining domestic and foreign experiences, we put forward improvement measures, and then put forward the future development direction of rural waste disposal in Shandong Province.
\end{abstract}

\section{Introduction}

"Innovation, coordination, green, open, sharing" is to lead the development of China's overall development of the five concepts. The green development emphasizes sustainable development, the harmonious development of man and nature. In the pursuit of green environment, the rural waste disposal more and more attention by the community, the future development potential is huge, with strong research value. Rural is the largest provider of ecological products, to solve the "garbage around village" is placed in front of us an important and urgent task.

Shandong Province made a positive response to the call of the party and the government, remediation of rural environmental health, at the end of 2015 the first to achieve the integration of urban and rural sanitation full coverage. $98 \%$ of rural cleaners in the province, $99 \%$ of domestic garbage collection containers, $96 \%$ of the timely removal of garbage in rural areas, the stock of garbage cleaning rate of $89.5 \%, 95 \%$ satisfaction. In addition, the integration of urban and rural sanitation in Shandong Province has also caught the PPP (government and social capital cooperation) of the "car." Premier Li Keqiang repeatedly proposed to promote government and social capital cooperation model, the convergence of social forces to increase the supply of public goods and services. In 2015 the establishment of Shandong Province Urbanization Investment Fund includes rural waste disposal.

\section{The Garbage Disposal Problem in Shandong Province}

The Integration of Urban and Rural Sanitation Renovation is not Complete and There are Regional Differences in Governance. Survey data show that in the realization of urban and rural sanitation integration model, there are still villagers reaction to the village where the implementation of rural waste incineration, disposal and other disposal methods, the proportion of about 30\% (see Figure 5). This shows that the integration of urban and rural sanitation work is not complete, in rural areas there are still behind the garbage disposal.

In the field research, through the photo shooting, video recording, found in different parts of the rural waste management situation there are regional differences. Although some areas have achieved the integration of urban and rural sanitation full coverage, but the treatment effect is not good. There are loopholes and deficiencies in the regulatory mechanism, operational processes and other aspects. 
Lack of Financial Funds in Rural Areas and Rural Waste Management Costs Are High. The survey data show that $83 \%$ of the rural areas in the surveyed areas are collectively collected free of charge and the villagers are charged $7.8 \%$ (see Figure 1). In recent years, the Government to increase rural waste management funds to accelerate the construction of rural waste disposal infrastructure, but there are still "short supply" phenomenon. At the same time, sanitation team, system and system construction, environmental protection laws and regulations of the publicity, training and implementation work also need financial support.

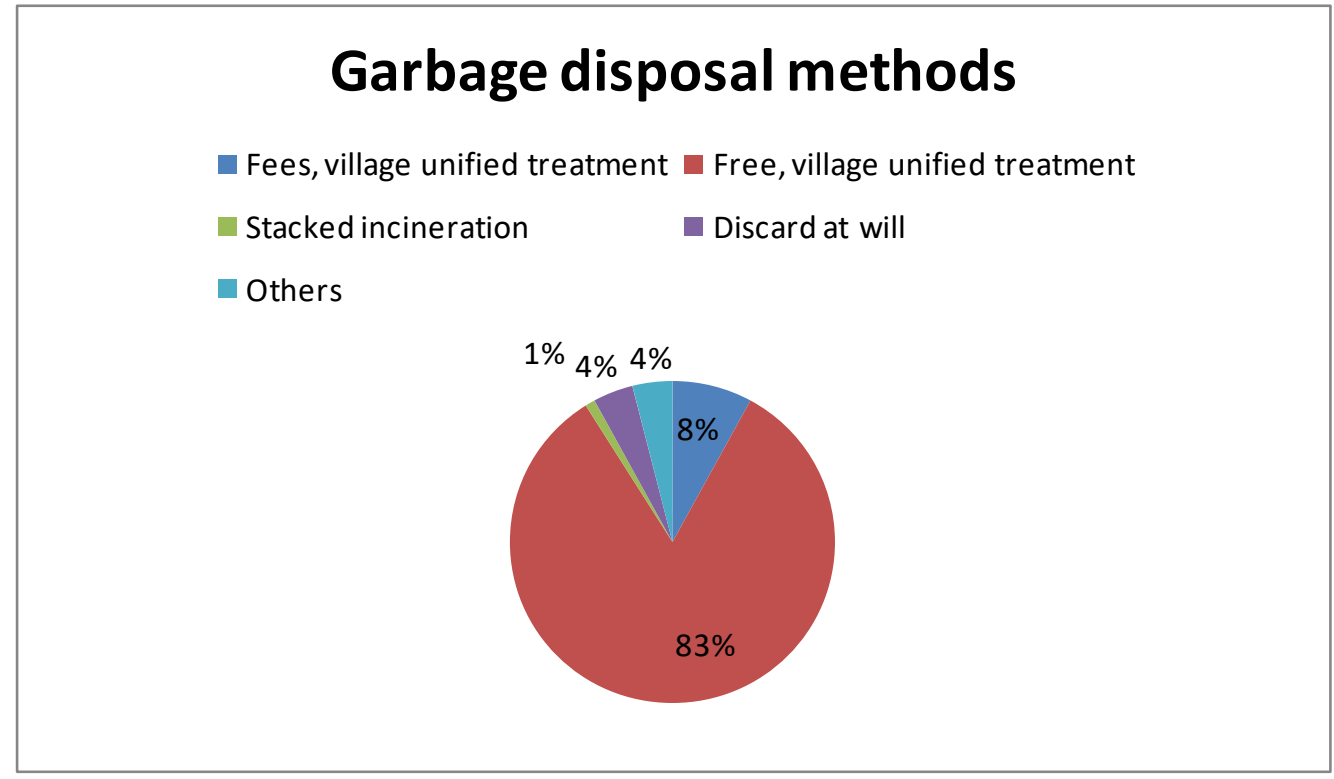

Figure 1Ways of disposing garbage in the village where respondents are located

Rural residents have developed long-term bad habits and relatively weak awareness of environmental protection, coupled with the scattered rural living is difficult to form economies of scale makes the cost of rural waste management, infrastructure construction difficulties.

Farmers Need to Deal with Agricultural Waste and It Has Not Yet Formed a Treatment System. Survey data show that $82 \%$ of the villagers think that it is necessary to deal with agricultural waste, only $5 \%$ of the villagers believe that agricultural waste disposal is optional, not necessary (see Figure 2). At present, the main measures for rural production of garbage is the villagers' self-recovery, but discarded fields and incineration also accounted for a large proportion.

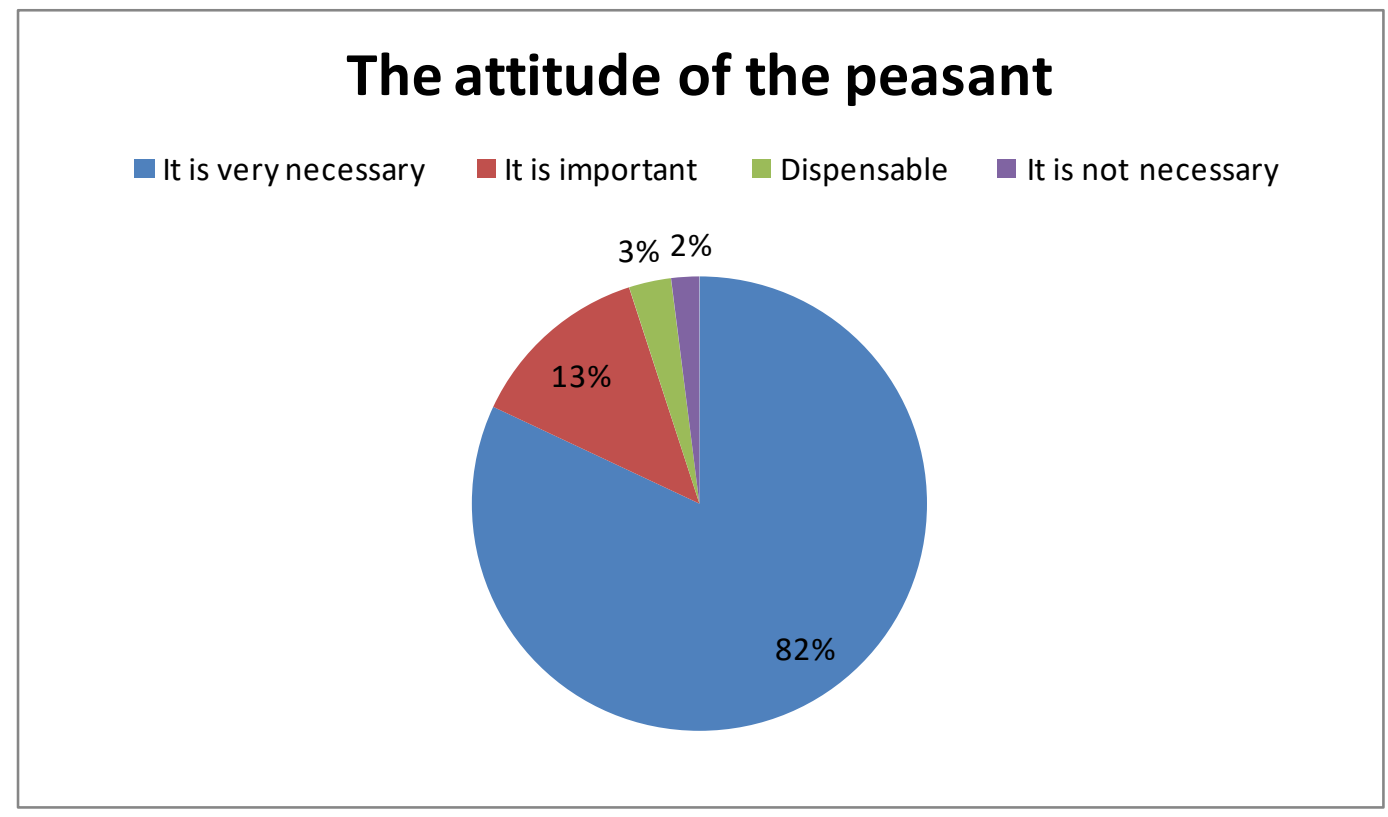

Figure 2 Attitudes of respondents to agricultural waste 
Agricultural production Landfill or incineration can have a negative impact on the rural environment and affect the quality of agricultural products. At present, the rural waste production has not yet formed a systematic system. In some areas, the rural production rubbish has been collected and remitted at special time or consulted with the local village committee, and the agricultural waste has been collected and concentrated. This intermittent treatment model is difficult to maintain long-term environmental clean and tidy farmland in Shandong Province and the current rural waste disposal is a common problem.

The Education Level of the Villagers Restricted the Improvement of Environmental Awareness of the Villagers. According to the survey data, villagers with low educational level have adopted more discarding and incineration of rural living and production waste than villagers with higher educational level. The villagers who have received the education level of junior middle school or above have a certain understanding of the classification of rural garbage, and a large proportion of them are willing to carry out the classification of rural garbage. For rural areas, the lower the level of education groups generally middle-aged villagers.

Through the analysis we can see that to improve the villagers environmental awareness, the end result in less educated middle-aged villagers, and this part of the villagers occupy the majority of the total number of villagers, long-established habits is difficult to change in a short time, One of the main reasons for the incomplete management of rural waste.

PPP Mode of Rural Waste Management System Needs to Deepen Reform. At present, environmental sanitation management, sanitation services, sanitation supervision by the majority of the government's environmental administrative departments at the level of overall responsibility. This system has many drawbacks, such as capital investment, quality of service, supervision and implementation of the implementation of the results, rewards and punishments to fulfill the full effect of such aspects is difficult to fully play a role in the system of financial support, self-management, self-support and self-supervision.

In this case, with the PPP model to promote the reform of environmental sanitation system, broaden the sanitation fund investment and financing channels, public sanitation services to the market, through the operation of the market, "let professional people do professional things" to further optimize the allocation of resources, For the public to provide quality products and services.

\section{The Necessity of Application of PPP Mode in Rural Waste Disposal}

Its Effect Is Better Compared to Other Rural Waste Treatment Model. PPP model is a win-win or win-win cooperation based on the concept, it is in the sanitation of public utilities investment, construction, operation and service has a broad application prospects. With the rapid development of China's economy and the integration of urban and rural sanitation work, rural residents have become increasingly demanding on the environment, sanitation facilities and equipment construction and operation and management level need to be further enhanced.

Urban and rural sanitation cause only rely on the government to complete the supply will lead to a lack of market competition incentive mechanism and inefficient; service supply vulnerable to macroeconomic policy impact of service costs by government budget restrictions affect the garbage disposal facilities update and maintenance. If relying on the "private" business model and voluntary self-service model will lead to the lack of government macro-control, and then lead to different standards, vicious competition.

It Can Effectively Reduce the Financial Burden on the Government to Cut Costs Overruns. In view of the huge debt burden faced by the government infrastructure construction, the PPP model has diversified the financing channels through the introduction of private capital to build rural waste disposal projects, and increased the sources of funds for the construction of rural waste disposal facilities, thus reducing the government's financial burden. At the initial stage of project construction, the government and social capital participate in the project feasibility study, financing, construction and so on, so as to economize the project expenditure technically and economically. Only when the project is completed and approved by the government can the private sector profit from it, which will help reduce project costs and improve efficiency. 
Through the "User Pay" to Improve the Environmental Awareness of the Villagers to Strengthen Supervision of Sanitation Work. At present, Shandong Province has been built or under construction in the rural waste disposal PPP projects are mostly involved in waste incineration power plants, garbage transfer stations and urban and rural sanitation integration projects. Most of the PPP projects use "user-pays" and "feasibility gap" payments. In this way, villagers realized that they were paying for their own sanitation services, so they had a strong sense of autonomy in their daily rural environment maintenance and garbage disposal. At the same time, the village cleaning staff is the enterprise staff and the villagers can supervise the work of cleaning report, which is conducive to improving the quality of sanitation work.

The Market Operation of the "Professional People to Do Professional Things" to Improve the Operational Efficiency and Quality. In the traditional government supply mode, the government is both a "referee" and an "athlete". It is both a manager and a supervisor in the rural waste disposal, which leads to a great decrease of the quality and efficiency of the rural waste disposal. Through the PPP model, the introduction of professional sanitation company, market-oriented operation, to achieve the separation of the stem. Traditional rural waste disposal model often leads to rural road cleaning is not complete and garbage removal is not timely, the phenomenon of loose regulation. Rural waste disposal market-oriented operation, the company's assessment of the work of cleaning staff; at all levels of government performance evaluation of the company; the villagers on the management of rural waste supervision and reporting, thus establishing a benign supervision mechanism, effectively improving the rural waste management Efficiency and quality.

"Intelligent Sanitation" Is Widely Used in Rural Waste Disposal, Reducing Operating and Regulatory Costs. "Intelligent sanitation" This view was first proposed by the Changyi Kang Jie, relying on Internet of things technology and mobile Internet technology, through the people, cars, objects, and the whole process of real-time monitoring, so as to improve sanitation quality and reduce operating costs. Professional sanitation company is relative to the government departments have advanced sanitation supervision technology, with digital management platform. At present, the general realization of the garbage truck GPS positioning technology, through the garbage truck daily working distance, fuel consumption and other monitoring to protect the timely disposal of rural waste, while saving the cost can be put into other areas of sanitation, effective of the operating costs.

The Construction of the Project Is of Long-Term Nature and Is Conducive to Safeguarding Various Interests. PPP projects in rural waste disposal most of the cooperation period of more than 10 years, relative to the shorter duration of the project, to avoid the excessive emphasis on short-term interests, each other at the expense of each other's interests to gain their own interests. In the implementation of the PPP project, the government and private enterprises are also involved in project construction, benefit sharing and risk sharing, and effectively strengthen the communication between the two sides. In the long-term project construction, the government asked enterprises to provide high-quality rural sanitation quality, business requirements for profit income, villagers require clean sanitation. The interests of the parties keep balance and consultation, the interests made integration and perfection in the process of continuous project, and ultimately to maximize the total social benefits.

\section{References}

[1] Zhou Xianjin, Li Songming. The Study on Countermeasures and Social Environment Factors Affected by the Ideological and Political Education[J]. Heilongjiang Higher Education Research .2007.01: 77

[2] Yu Jiaming. Characteristics of "After 90s" Youth Group and Education Countermeasures[J]. China Youth Research .2010.01: 56

[3] Li Mingshan. On the Network Environment on the Management of College Students and the Impact of Change [OL] http://www.lunwentianxia.com.2012.12:18 
[4] Li Xiangping. Chinese Reform and its Belief Transformation[J]. Journal of Shanghai University (Social Science Edition) 2013.01: 52

[5] Chen Dianlin, WANG Tianen. Study on the Influencing Factors of College Students' Ideological and Political Education[J]. Journal of Tianzhong University, 2009.06: 